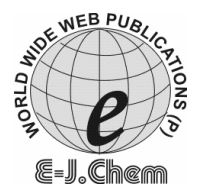

\title{
Synthesis of Diindolylmethanes (DIMs) Catalyzed by Silicotungstic Acid by Grinding Method
}

\author{
JI-TAI LI* and SHAO-FENG SUN
}

\begin{abstract}
Key Laboratory of Analytical Science and Technology,
Hebei Province; Key Laboratory of Medical Chemistry and Molecular Diagnosis, Ministry of Education; College of Chemistry and Environmental Science, Hebei University, Baoding 071002, P. R. China.
\end{abstract}

lijitai@hbu.cn

Received 20 November 2009; Accepted 15 January 2010

\begin{abstract}
The synthesis of diindolylmethanes (DIMs) via the condensation of indole and aromatic aldehydes catalyzed by silicotungstic acid was carried out in $68 \%$ $98 \%$ yields at room temperature within 1 5 min by grinding. This method provides several advantages such as operational simplicity, higher yield and environment friendly.
\end{abstract}

Keywords: Grinding, Silicotungstic acid, Diindolylmethanes, Synthesis, Catalysis.

\section{Introduction}

The reactions of indoles have received much attention as a number of their derivatives, which found applications in the field of pharmaceuticals, agrochemicals and material sciences ${ }^{1}$. Among the indole derivatives, the diindolylmethanes (DIMs) have potential uses in biological activities such as antibacterial and antitumor properties ${ }^{2}$. The principal synthetic avenues to the DIMs comprise the protic acid, Lewis acid or solid acid-catalysed reaction of indole with aldehydes (or ketones). In view of that, several synthetic methods for the preparation of DIMs have been reported by using catalysts such as: $\mathrm{InCl}_{3}$ or $\mathrm{In}(\mathrm{OTf})_{3}{ }^{3 \mathrm{a}}$, $\mathrm{Ln}(\mathrm{OTf})_{3}{ }^{3 \mathrm{~b}}, \mathrm{LiClO}_{4}{ }^{3 \mathrm{c}}, \mathrm{VCl}_{3}{ }_{3 \mathrm{~d}}, \mathrm{CuBr}_{2}{ }^{3 \mathrm{e}}$, trichloro-1,3,5-triazine ${ }^{3 \mathrm{f}}$, zeolite $^{3 \mathrm{~g}, 3 \mathrm{~h}}$, sulphamic ${ }^{3 \mathrm{i}}$, polyindole salt ${ }^{3 \mathrm{j}}, \mathrm{RE}(\mathrm{PFO})_{3}{ }^{3 \mathrm{k}}$, ultrasound/CAN ${ }^{31}$, montmorillonite $\mathrm{K} 10^{3 \mathrm{~m}}$, ultrasound/aminosulfonic $\mathrm{acid}^{3 \mathrm{n}}$, iodine $\mathrm{e}^{4}, p$-toluenesulfonic $\mathrm{acid}^{5}$, fluoroboric acid adsorbed on silica gel ${ }^{6}$, phosphorus pentoxide/silica gel $\left(\mathrm{P}_{2} \mathrm{O}_{5} / \mathrm{SiO}_{2}\right)^{7}$, diammonium hydrogen phosphate ${ }^{8}$, ammonium chloride ${ }^{2}$, $\mathrm{ZnO}^{9 \mathrm{a}}$, Montmorillonite $\mathrm{K} 10-\mathrm{ZnCl}_{2}{ }^{9 \mathrm{~b}}, \mathrm{Zr}-\mathrm{OPO}_{3} \mathrm{H}^{10}$ and $\mathrm{H}_{6} \mathrm{P}_{2} \mathrm{~W}_{18} \mathrm{O}_{62}{ }^{11}$. However, in spite of their potential utility, some of the reported methods suffer from drawbacks such as long reaction times, expensive catalysts, low yields and cumbersome product isolation procedures.

Heteropolyacids are remarkable catalysts that are used in both homogenous and heterogeneous conditions. Their application as acid catalysts has been already reviewed ${ }^{12}$. Silicotungstic acid is a solid heteropolyacid that has been used for the synthesis of quinoline ${ }^{13}$, 
1,3,5-trioxane $e^{14}$, ester and acetaldehydes (or ketones) ${ }^{15}$ and cyclohexanone ethylene glycol ketal $^{16}$. Murrgan ${ }^{12}$ and his colleagues reported the synthesis of diindolyl pyrazolyl methanes and 3-alkylated indoles catalyzed by silicotungstic acid to give 85\% 95\% yields and $85 \%$ 93\% yields respectively. Synthesis of 5-arylidene barbituric acid catalyzed by silicotungstic acid $\left(\mathrm{SiO}_{2} \cdot 12 \mathrm{WO}_{3} \cdot 24 \mathrm{H}_{2} \mathrm{O}\right)$ has been carried out in $41 \% \sim 99 \%$ yields ${ }^{17}$.

Grinding method often leads to shorter reaction time, increased yields, easier workup, matches with green chemistry protocols, has been considered as an useful protocol in organic synthesis ${ }^{7,18,19}$. Recently, our laboratory has used the grinding method for the synthesis of 5 -arylidene barbituric acid catalyzed by anhydrous zinc chloride ${ }^{18 \mathrm{~b}}$ or aminosulfonic acid ${ }^{18 \mathrm{c}}$

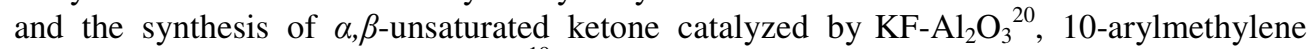
anthrone catalyzed by $\mathrm{KF}-\mathrm{Al}_{2} \mathrm{O}_{3}{ }^{19}$ and di(indolyl)methanes (DIMs) catalyzed by montmorillonite $\mathrm{K} 10-\mathrm{ZnCl}_{2}{ }^{9 \mathrm{~b}}$. In this paper, we report an efficient preparation of diindolylmethanes (DIMs) catalyzed by silicotungstic acid $\left(\mathrm{SiO}_{2} \cdot 12 \mathrm{WO}_{3} \cdot 24 \mathrm{H}_{2} \mathrm{O}\right)$ by grinding at room temperature (Scheme 1).

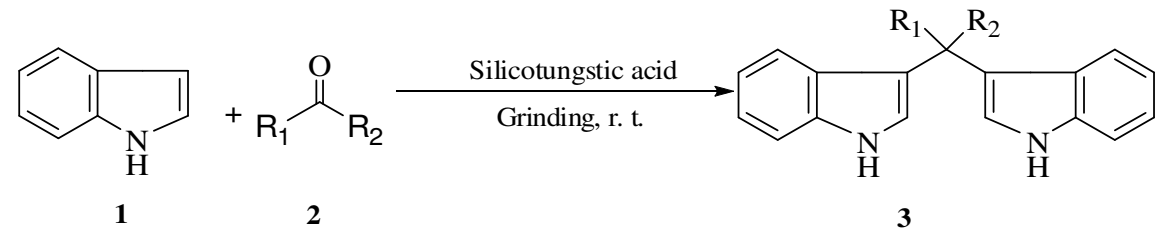

\section{Experimental}

Scheme 1. Synthesis of diindolylmethanes

Liquid aldehydes or ketones were purified by distillation before using. Melting points were uncorrected. ${ }^{1} \mathrm{H}$ NMR spectra were measured on a Bruker AVANCE III-600 (600 MHz) spectrometer using TMS as internal standard and $\mathrm{CDCl}_{3}$ as solvent. Mass spectra were determined on a Agilent Technologies 6310 Lon Trap LC/MS.

\section{General procedure of condensation of indole with aldehydes or ketones}

Aldehydes or ketones (1, $0.5 \mathrm{mmol})$, indole $(\mathbf{2}, 1 \mathrm{mmol})$ and silicotungstic acid $\left(\mathrm{SiO}_{2} \cdot 12 \mathrm{WO}_{3} \cdot 24 \mathrm{H}_{2} \mathrm{O}\right)(33 \mathrm{mg}, 0.01 \mathrm{mmol})$ were mixed in a mortar and ground at room temperature for the period of time as indicated in Table 2. The reaction was followed by TLC. After the completion of the reaction, the mixture was extracted with EtOAc $(3 \times 15 \mathrm{~mL})$, washed with water $(3 \times 10 \mathrm{~mL})$ and then dried with anhydrous magnesium sulfate over night and filtered. The solvent was evaporated under reduced pressure to give the crude product, which was purified by column chromatography on silica gel eluted with petroleum ether or the mixture of EtOAc and petroleum ether. The authenticity of the known compounds $\mathbf{3 a} \sim \mathbf{3 e}, \mathbf{3 h} \sim \mathbf{3 m}$ and 3o 3q was established by comparing their melting points with that reported in literatures ${ }^{4,21 \sim 23}$, the rests (3f, $\mathbf{3 g}$ and $\mathbf{3 n})$ were established by ${ }^{1} \mathrm{H}$ NMR and mass spectra.

\section{3-((1H-Indol-3-yl)(2-nitrophenyl)methyl)-1H-indole (3f)}

Light red solid, m.p. $98 \sim 100{ }^{\circ} \mathrm{C}$ (ethyl acetate/petroleum ether); ${ }^{1} \mathrm{H}$ NMR $\delta: 6.68$ (d, J=2.6 Hz, $3 \mathrm{H}), 7.01 \sim 7.43$ (m, 11H), $7.84 \sim 7.85$ (d, J=7.6 Hz, 1H), 7.96 (brs, 2H) ppm; MS (ESI) $\mathrm{m} / z$ : $390\left(\mathrm{M}+\mathrm{Na}^{+}\right)$.

\section{3-((1H-Indol-3-yl)(3-nitrophenyl)methyl)-1H-indole (3g)}

Light yellow solid, m.p. 88 90 ${ }^{\circ} \mathrm{C}$ (ethyl acetate/petroleum ether); ${ }^{1} \mathrm{H}$ NMR $\delta: 6.00(\mathrm{~s}, 1 \mathrm{H})$, $6.67 \sim 6.68$ (d, J=2.3 Hz, 2H), 7.01 7.45 (m, 9H), 7.69 7.70 (d, J=7.8 Hz, 1H), 8.00 (brs, 2H), 8.07 8.21 (m, 2H) ppm; MS (ESI) $m / z: 390\left(\mathrm{M}+\mathrm{Na}^{+}\right)$. 


\section{3-((1H-Indol-3-yl)(cyclohexyl)methyl)-1H-indole (3n)}

White solid, m.p. $165 \sim 166{ }^{\circ} \mathrm{C}$ (ethyl acetate/petroleum ether); ${ }^{1} \mathrm{H}$ NMR $\delta: 1.53 \sim 1.68(\mathrm{~m}, 6 \mathrm{H})$, $2.54 \sim 2.55\left(\mathrm{t}, J_{I=} 5.4 \mathrm{~Hz}, J_{2}=11.9 \mathrm{~Hz}, 4 \mathrm{H}\right), 6.87 \sim 7.56$ (m, 10H), 7.92 (brs, 2H) ppm; MS (ESI) $m / z: 337\left(\mathrm{M}+\mathrm{Na}^{+}\right)$.

\section{Results and Discussion}

The influence of the amount of catalyst on the reaction was examined. As shown in Table 1, the amount of silicotungstic acid had a significant effect on the reaction yield. When using $0.005 \mathrm{mmol}, 0.01 \mathrm{mmol}, 0.02 \mathrm{mmol}$ catalysts, the yield of 3a was $57 \%$ (Entry 2), $95 \%$ (Entry 3), 96\% (Entry 4) respectively. In the absence of silicotungstic acid, the yield of 3a was only $11 \%$ (Entry 1). It seems that changing the amount of molar ratio of silicotungstic acid (Entries 3, 4) had not a significant effect on the yield of 3a. So we chose $0.01 \mathrm{mmol}$ silicotungstic acid as the optimum amount.

Table 1. The effect of amount of silicotungstic acid on the yield of $\mathbf{3 a}$ by grinding.*

\begin{tabular}{cccc}
\hline Entry & Catalyst, mmol & Grinding time, min & Isolated yield, $\%$ \\
\hline 1 & 0 & 5 & 11 \\
2 & 0.005 & 2 & 57 \\
3 & 0.01 & 2 & 95 \\
4 & 0.02 & 2 & 96 \\
\hline
\end{tabular}

*Substrate benzaldehyde $0.5 \mathrm{mmol}$, indole $1.0 \mathrm{mmol}$.

Table 2. Synthesis of di(indolyl)methanes from aldehydes (or ketones) and indole catalyzed by silicotungstic acid by grinding.

\begin{tabular}{ccccccc}
\hline Entry & $\mathrm{R}_{1}$ & $\mathrm{R}_{2}$ & Product & $\begin{array}{c}\text { Grinding time, } \\
\text { min }\end{array}$ & $\begin{array}{c}\text { Yield, } \\
\%\end{array}$ & m.p., ${ }^{\mathrm{o}} \mathrm{C}[\mathrm{lit}]$ \\
\hline 1 & $\mathrm{C}_{6} \mathrm{H}_{5}$ & $\mathrm{H}$ & $\mathbf{3 a}$ & 2 & 95 & $88-90(93-94)^{4 \mathrm{a}}$ \\
2 & $4-\mathrm{CH}_{3} \mathrm{OC}_{6} \mathrm{H}_{4}$ & $\mathrm{H}$ & $\mathbf{3 b}$ & 2 & 77 & $190-192(188-191)^{4 \mathrm{a}}$ \\
3 & $2-\mathrm{CH}_{3} \mathrm{OC}_{6} \mathrm{H}_{4}$ & $\mathrm{H}$ & $\mathbf{3 c}$ & 2 & 98 & $174(174-176)^{4 \mathrm{a}}$ \\
4 & $4-\mathrm{CH}_{3} \mathrm{C}_{6} \mathrm{H}_{4}$ & $\mathrm{H}$ & $\mathbf{3 d}$ & 2 & 68 & $96-98(98-100)^{4 \mathrm{a}}$ \\
5 & $4-\mathrm{ClC}_{6} \mathrm{H}_{4}$ & $\mathrm{H}$ & $\mathbf{3 e}$ & 5 & 87 & $76(76-77)^{4 \mathrm{a}}$ \\
6 & $2-\mathrm{NO}_{2} \mathrm{C}_{6} \mathrm{H}_{4}$ & $\mathrm{H}$ & $\mathbf{3 f}$ & 1 & 98 & $98-100$ \\
7 & $3-\mathrm{NO}_{2} \mathrm{C}_{6} \mathrm{H}_{4}$ & $\mathrm{H}$ & $\mathbf{3 g}$ & 3 & 98 & $88-90$ \\
8 & $4-\mathrm{NO}_{2} \mathrm{C}_{6} \mathrm{H}_{4}$ & $\mathrm{H}$ & $\mathbf{3 h}$ & 1 & 97 & $218-219(217-219)^{4 \mathrm{a}}$ \\
9 & $2-\mathrm{ClC}_{6} \mathrm{H}_{4}$ & $\mathrm{H}$ & $\mathbf{3 i}$ & 3 & 98 & $74-75(72-74)^{4 \mathrm{a}}$ \\
10 & $3-\mathrm{ClC}_{6} \mathrm{H}_{4}$ & $\mathrm{H}$ & $\mathbf{3 j}$ & 3 & 97 & $84-86(83-85)^{4 \mathrm{a}}$ \\
11 & $\mathrm{C}_{6} \mathrm{H}_{5} \mathrm{CH}_{4} \mathrm{CH}$ & $\mathrm{H}$ & $\mathbf{3 k}$ & 3 & 95 & $98(98-99)^{4 \mathrm{a}}$ \\
12 & $4-\mathrm{NO}_{2}-\mathrm{C}_{6} \mathrm{H}_{4}$ & $\mathrm{CH}$ & $\mathbf{3 1}$ & 15 & 16 & $234-236(239-240)^{4 \mathrm{a}}$ \\
13 & $4-\mathrm{Cl}_{3}-\mathrm{C}_{6} \mathrm{H}_{4}$ & $\mathrm{CH}$ & $\mathbf{3 m}$ & 25 & 28 & $106-108(109-111)^{4 \mathrm{a}}$ \\
14 & $-\left(\mathrm{CH}_{2}\right)_{5}$ & & $\mathbf{3 n}$ & 2 & 30 & $165-166(162-164)^{18 c}$ \\
15 & $\mathrm{CH}_{3}$ & $\mathrm{CH}$ & $\mathbf{3 o}$ & 10 & 24 & $66-68(64-66)^{21}$ \\
16 & $\mathrm{CH}_{3}$ & $\mathrm{H}$ & $\mathbf{3 p}$ & 20 & 49 & $160(161-162)^{22}$ \\
17 & $\mathrm{CH}_{3} \mathrm{CH}_{2} \mathrm{CH}_{2}$ & $\mathrm{H}$ & $\mathbf{3 q}$ & 20 & 49 & $106-108(109)^{23}$ \\
\hline
\end{tabular}

A series of experiments for the synthesis of diindoylmenthanes were performed via the condensation of indole $(1,1 \mathrm{mmol})$ and aldehydes or ketones $(2,0.5 \mathrm{mmol})$ catalyzed by silicotungstic acid (33 mg, $0.01 \mathrm{mmol})$. The results were summarized in Table 2 . 
As shown in the Table 2, the method presented here represented an efficient procedure in terms of high yield, mild reaction conditions, and easy workup. For example, 3 -((1H-Indol-3-yl)(2-nitrophenyl)methyl)- $1 H$-indole (3f) was previously prepared in $84 \%$ yield catalyzed by $\mathrm{ZnO}$ with stirring at $80^{\circ} \mathrm{C}$ for $45 \mathrm{~min}^{9 \mathrm{a}}$, whereas present procedure offered 3f in $98 \%$ yield at r.t. within $1 \mathrm{~min}$.

In the present procedure, the reaction was very tolerant of aromatic aldehydes carrying either electron-withdrawing or electron-donating substituent groups. However, the condensation of indole and ketones (Entries 12 15) or aliphatic aldehydes (Entries 16, 17) was carried out in lower yields. This indicates that the method has some limitations with respect to ketones or aliphatic aldehydes.

\section{Conclusion}

In summary, we have developed an efficient, environment friendly route to the synthesis of diindolylmethanes via the condensation of indole with aromatic aldehydes catalyzed with silicotungstic acid by grinding. But the method has some limitations with respect to ketones or aliphatic aldehydes.

\section{Acknowledgments}

We thank Natural Science Foundation of Hebei Province (B2006000969), China, for financial support.

\section{References}

1. Jitendra R S, Kalpesh D P and Radha V J, Catal Commun., 2008, 9, 1071.

2. Javad A, Fatemeh T and Mohammad R M, Catal Commun., 2007, 8, 1117.

3. (a) Nagarajan R and Perumal P T, Tetrahedron, 2002, 5, 1229; (b) Chen D, Yu L and Wang P G, Tetrahedron Lett., 1996, 37, 4467; (c) Yadav J S, Reddy B V S, Murthy C V S R, Kumar G M and Madan C, Synthesis, 2001, 783; (d) Rajitha B, Reddy P N and Kumar B S, J Chem Res Synop., 2005, 222; (e) Mo L P, Ma Z C and Zhang Z H, Synth Commun., 2005, 1997; (f) Sharma G V M, Reddy J J, Lakshmi P S and Krishna P R, Tetrahedron Lett., 2004, 45, 7729; (g) Karthik M, Tripathi N M, Gupta N M, Palanichamy M and Murugesan V, Catal Commn., 2004, 5, 371; (h) Reddy A V, Ravinder K, Reddy V L N, Goud T V, Ravikanth V and Venkateseswarlu Y, Synth Commun., 2003, 33, 3687; (i) Singh P R, Singh D U and Samant S D, Synth Commun., 2005, 35, 2133; (j) Palaniappan S and John A, J Mol Catal A: Chem., 2005, 242, 168; (k) Wang L M, Han J W, Tian H, heng J, Fan Z Y and Tang X P, Synlett., 2005, 337; (1) Zeng X F, Ji S J and Wang S Y, Tetrahedron, 2005, 61, 10235; Ramesh C, Banerjee J, Pal R and Das B, Adv Synth Catal., 2003b, 345, 557; (m) Chakrabarty M, Ghosh N, Basak R and Harigaya Y, Tetrahedron, 2002, 43, 4075. (n) Li J T, Dai H G, Xu W Z and Li T S, Ultrason Sonochem., 2006, 13, 24.

4. (a) Ji S J, Wang S Y, Zhang Y and Loh T P, Tetrahedron, 2004, 60, 2051; (b) Bandgar B P and Shaikh K A, Tetrahedron Lett., 2003, 44, 1959; (c) Selvam J J, Srinivasulu M, Suryakiran N, Suresh V, Reddy S M and Venkateswarlu Y, Synth Commun., 2008, 38, 1760; (d) Khalafi-Nezhad A, Parhami A, Zare A, Zare A R M, Hasaninejad A and Panahi F, Synthesis, 2008, 4, 617; (e) Hasaninejad A, Zare A, Sharghi H, Shekouhy M, Khalifeh R, Beni A S and Zare A R M, Can J Chem., 2007, 85, 416; (f) Minoo D, Mostafa B, Seyedeh C A, Shaghayegh A A and Reza R A, Lett Org Chem., 2008, 5, 490.

5. Pasha M A and Jayashankara V P, J Pharmacol Toxicol., 2006, 1, 585.

6. Bandgar B P, Abasaheb, Patil V and Kamble V T, ARKIVOC, 2007, 16, 252.

7. Alireza H, Abdolkarim Z, Hashem S, Khodabakhsh N and Mohsen S, ARKIVOC, 2007, 14, 39. 
8. Minoo D, Peyman S, Mostafa B, Yasamin V and Shadi K, Monatsh Chem., 2007, 138, 595.

9. (a) Mona H S, Synth Commun., 2008, 38, 832; (b) Li J T and Lin Z P, Chin J Org Chem., 2008, 28, 1238.

10. Nadkarni S V, Gawande M B, Jayaram R V and Nagarkar J M, Catal Commun., 2008, 9, 1728.

11. Heravi M M, Ranjbar L, Derikvand F and Bamoharram F F, Catal Commun., $2007,8,289$.

12. (a) Murugan R and Reddy B S R, Tetrahetron., 2005, 61, 12275. (b) Okuhara T, Mi zuno N and Misono M, Appl Catal., A, 2001, 222, 63; (c) Misono M, Catal Rev., 1987, 29, 269.

13. Nagahara H, Kagawa H, Kagawa K, Iwaisako T and Komaki H, Angew Chem Int Ed., 2000, 9, 2102.

14. Lou Y M and Bai A M, Sci Tech Chem Indus., 2003, 11, 49.

15. Ouyang Y Z, Zou X Y and Peng Q J, J Jishou Univ (Nat. Sci. Ed.), 2000, 21, 53.

16. Kamakshi R and Reddy B S R, Catal Commun., 2007, 8, 825.

17. Li J T and Sun M X, Aust J Chem., 2009, 62, 353.

18. (a) Geng L J, Li J T and Wang S X, Chin J Org Chem., 2005, 25, 608; (b) Geng L J, Wang S X, Li J T and Liu C H, Chin J Org Chem., 2002, 22, 1047; (c) Li J T, Dai H G, Liu D and Li T S, Synth Commun., 2006, 36, 789.

19. Wang S X, Li J T, Yin Y H and Zhang Y, J Hebei Univ ( Nat Sci Ed.), 2003, 23, 385.

20. Wang S X, Li J T and Wang Z H, Chin J Org Chem., 2004, 24, 447.

21. Feng X L, Guan C J and Zhao C X, Synth Commun., 2004, 34, 487.

22. Bergman J, J Heterocycl Chem., 1970, 7, 1071.

23. Bandgar B P, Bettiger S V and Joshi N S, Monatsh Chem., 2004, 10, 1265. 


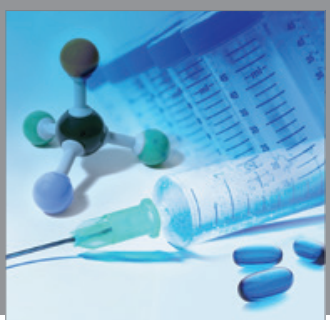

International Journal of

Medicinal Chemistry

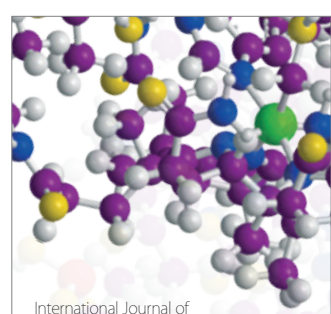

Carbohydrate Chemistry

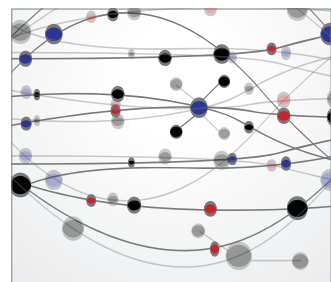

The Scientific World Journal
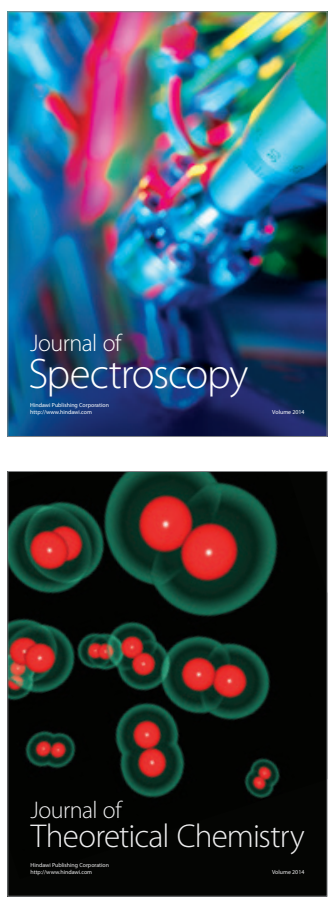
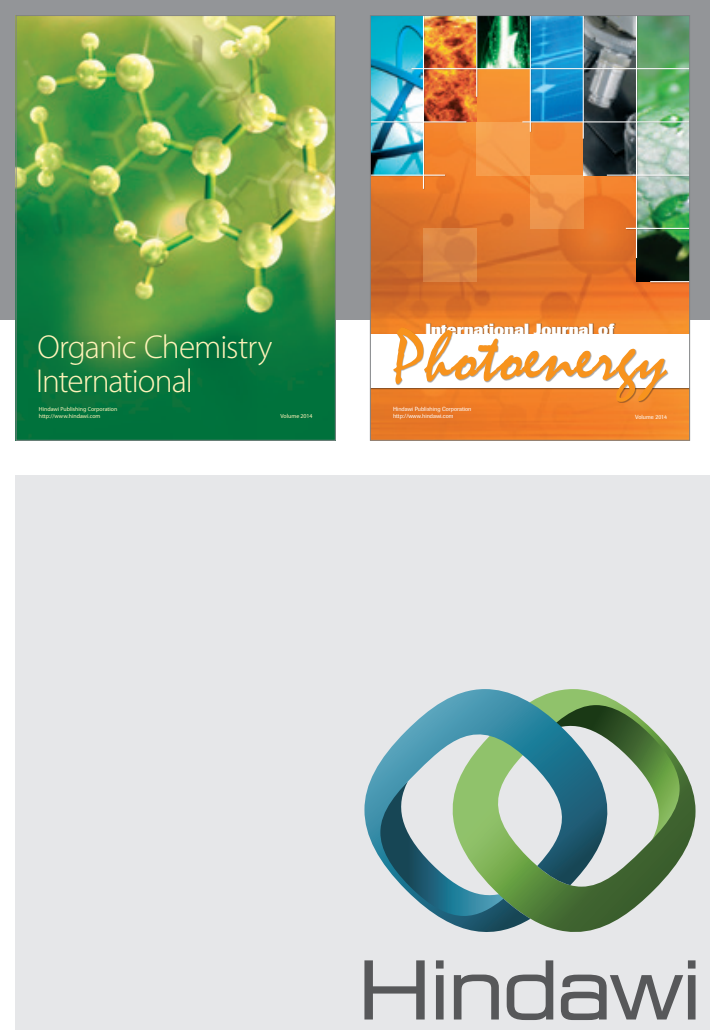

Submit your manuscripts at

http://www.hindawi.com
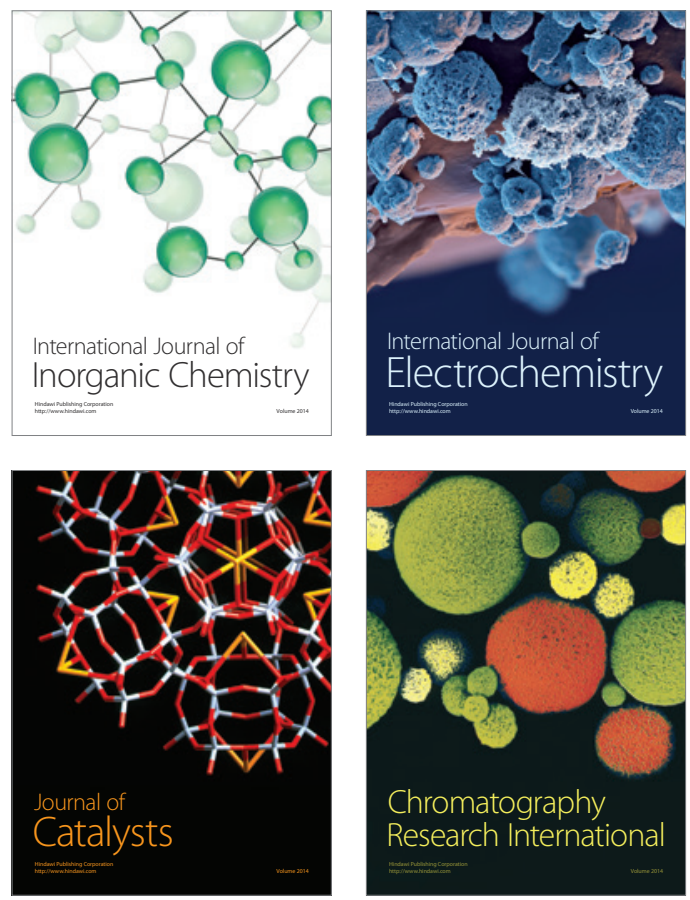
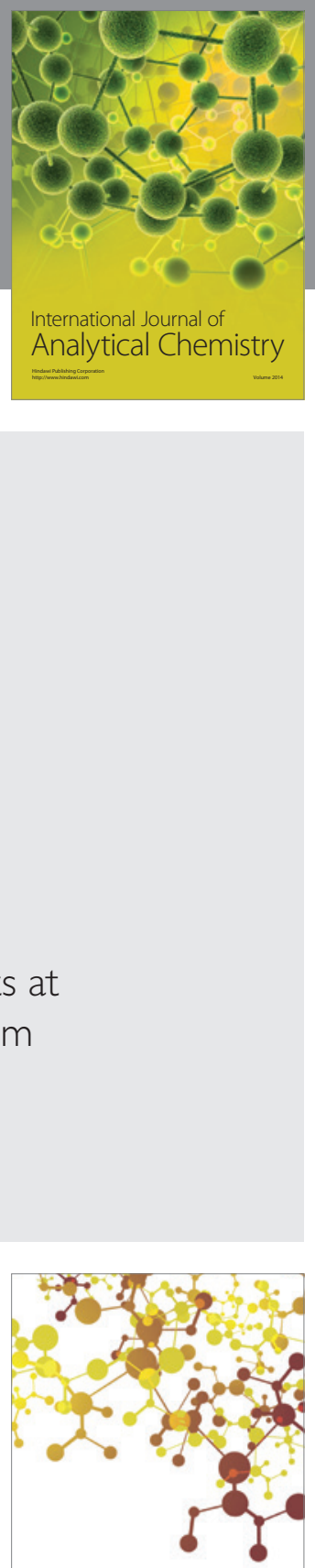

Journal of

Applied Chemistry
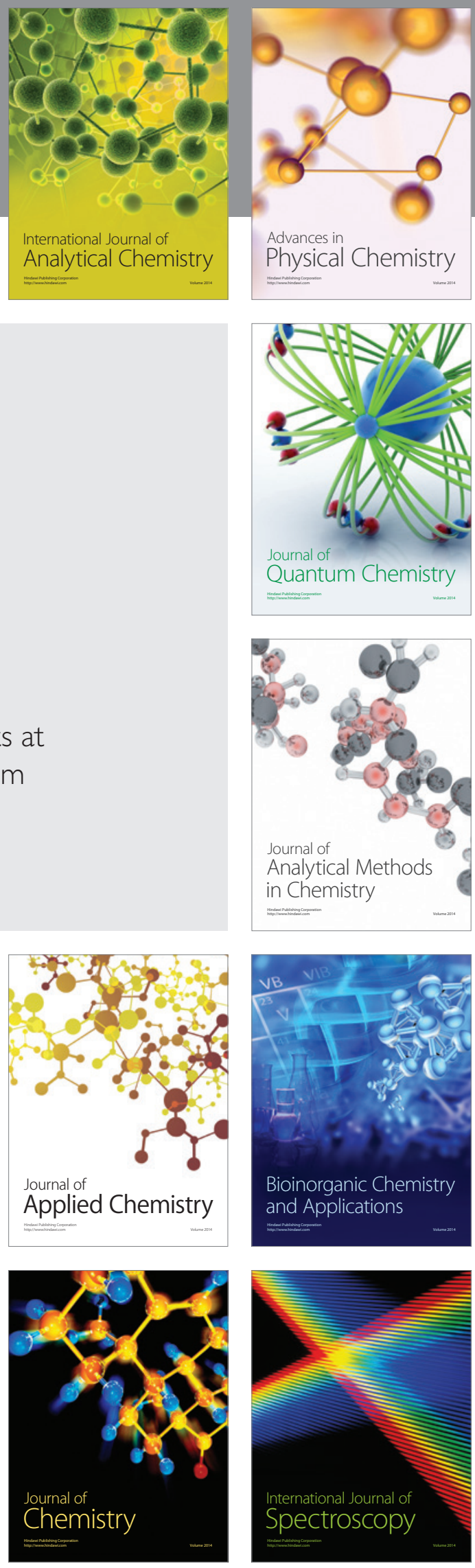